\title{
Discussion on optimization measures of relay protection technology in Intelligent Substation
}

\author{
Qianli Ma1 ${ }^{1}$,Zheng $\mathrm{Li}^{2}$ \\ ${ }^{1}$ Tsinghua University, China, ${ }^{2}$ National Power Grid Corp jibei Electric Power Co., Ltd. China \\ *Maqianlithu@126.com
}

Keywords: intelligent substation; relay protection; optimization strategy; analysis

\begin{abstract}
China's economy, promote our country science and technology level to a certain extent, but also led to the overall level of substation automation technology in China, through the construction of the implementation of intelligent substation in China, so that it can be in the running time can be more convenient, though is the Smart Substation at run time is more complex, and the adverse factors in the actual operation of power station will appear various, bring a certain impact on the safe operation of electronic. Therefore, it is necessary to continuously optimize the relay protection technology, and lay a solid foundation for the stable operation of smart substation. So this paper is the intelligent substation relay protection technology optimization measures corresponding analysis, on this basis put forward the content of the following.
\end{abstract}

\section{Introduction}

At present, the intelligent substation in construction, to a certain extent, the relay protection technology for scientific and effective optimization, not only can promote the long-term development of smart substation, but also improve its work efficiency. In recent years, our country has been through technological upgrading and the corresponding positive development of intelligent substation, promote the technology of relay protection has been well applied in the substation, which is an important technology in intelligent substation can not be ignored in a certain extent.

\section{Characteristic Analysis of Intelligent Substation}

\subsection{Intelligent Analysis of Primary Equipment}

For Smart Substation, a body capable of intelligent sensors and intelligent components effectively embedded into a body, so as to realize a device in the application and control in the process of comprehensive digital, but in actual operation, an equipment and protection equipment between the sampling data and control commands are transmitted through the cable, so an intelligent characteristic exists in the device through the intelligent sensor after a device is.

\subsection{Standardized Analysis of Communication Protocol}

In the intelligent substation, need to develop a more stringent standard, which can simulate information and communication interface to establish its equipment, promote the equipment between seamless connection, also need according to the relevant standards, each substation equipment and communication network for effective connection, to ensure that the information can achieve mutual sharing.Analysis of problems existing in electromechanical protection technology in.

\section{Technical Analysis in The Process of Relay Protection in Intelligent Substation}

\subsection{Analysis of Line Relay Protection}

Play the role can not be ignored is the line protection of relay protection, line protection to running state of the intelligent substation are used as the main basis, to provide a variety of protection, such as: start protection and direct jump off protection, avoid unnecessary operation fault. But in the intelligent substation line system, should be combined with the installation of smart substation monitoring interval measurement and control device is able to get a good run, surveying and mapping 
device to a certain extent in the surveying and mapping results reasonable transmission to COOSE network, based on the transmission of information to the induction, protection of the instructions issued.

\subsection{Analysis of Transformer Relay Protection}

For Smart Substation, transformer relay protection is the main category of process protection. For the back part of the device, the centralized installation mode can be applied, only in this way can the safety of the device be improved. In the relay protection, it is very important to protect a certain part of the non electric quantity. The main choice is cable connection and installation separately. At the same time, it can also connect it to the relay protection device. If the transformer is influenced by the risk of more serious, this module will appear tripping command, this command will further effective transmission to the common network system, to alleviate the effect of transformer station pressure, promote the security of the transformer are fully guaranteed to a certain extent.

\section{Analysis of Problems Existing in Relay Protection Technology in Intelligent Substation}

\subsection{There Is a Serious Shortage of Intelligent Level}

For Smart Substation, it is not just a simple concept, at the present stage domestic some departments do not have enough understanding of the smart substation, substation in China will further lead to most previous traditional modes of substation renovation and expansion, will be put into use, the concept of the construction led to a certain extent, our intelligence the substation can not fully realize the definition of "intelligence". Smart Substation put forward higher requirements for the number of its equipment, there is a large amount of resource consumption, in this context, resulting in the substation intelligent level there is a serious shortage.

\subsection{Due To The Lack of Standardization of The Interface Connector of The Equipment}

For Smart Substation, substation construction steps and its mechanism compared with the traditional operation for many complex, especially need a lot of equipment, have a corresponding interface between each device, therefore need to be connected through the appropriate route, in order to guarantee the normal operation of equipment. However, the actual work in the intelligent substation, equipment and equipment to realize the mutual connection between, must pass through a large number of wires to connect to the device interface without the effective, this will lead to its own equipment interface number increased, while different devices have different line interface, in order to make the formation of norms management will then increase the staff's workload to a certain extent.

\subsection{The Interference Caused by The External Environment to The Electromagnetic Equipment}

For the Smart Substation in the construction process, will be applied to more parts, these parts are for electronic transformer, such objective conditions so that the electromagnetic device will have a feature, that is environment noise, interference of electromagnetic devices such as fruit has been brought about by external environment. It will lead to some errors in the work, to a certain extent, can provide accurate and reliable data, which brings to the electromagnetic interference of the external environment will make the running speed of the intelligent substation appear lower, will also further increase the burden.

\section{Optimization Measures Analysis}

\subsection{Strengthen The Level of Intelligence}

In order to guarantee the realization of intelligent substation in the true sense, it should be on the basis of the original technology level of intelligent substation relay protection to strengthen protection for battle field, it is one of the effective measures to promote the level of intelligent substation to improve its working principle, the main performance is: through the corresponding network control, combined with the modern information technology applied to the computer, and then put all the information in the substation effectively mobilize, if the interference signal from the external environment, the computer can automatically start the implementation of protection device. Intelligent substation in all the information in the transmission process of heavy are forms of 
electronic signals, because the effective fusion of both modern information technology and mechanical and electrical protection technology which can shorten the time of transmission of information, but also can ensure the influence on the line number can also be timely response, the protection device will start in the first time, electromechanical this protection technology to meet the actual requirements of intelligent substation in a certain extent, improve the overall sensitivity of substation equipment comprehensive, in addition to make real-time protection for circuit.

\section{2combination of "Proximity Principle" Installation of Relay Protection Equipment}

For Smart Substation, relay protection equipment installation process, must comply with the principle of proximity, and to ensure the equipment in the vicinity of the relay protection equipment installation, the installation method can ensure the substation in the accident process, mechanical and electrical protection equipment can react in the first time, reduce the mechanical and electrical protection equipment to respond to time of the accident on the basis of the original, the maximum risk factor reduction to intelligent substation.

At the present stage of new integrated microcomputer line model is commonly used in most of the smart substation, relay protection equipment and electrical protection measures can work together, will work in the process of substation as the main basis, scientific and reasonable configuration of the circuit, the only way to install, can to some extent improve intelligence the stable and safe operation of the substation equipment, effectively avoid risks, leading to the staff's life is threatened. At the same time, in the new smart substation protection equipment for security, a method often used is the cable data acquisition mode, can implement the digital management of relay protection equipment of the mode, reduce the reaction time, combined with the use of the relationship between devices to achieve a reasonable division of equipment, promote intelligent substation equipment safety improved.

Text heads organize the topics on a relational, hierarchical basis. For example, the paper title is the primary text head because all subsequent material relates and elaborates on this one topic. If there are two or more sub-topics, the next level head (uppercase Roman numerals) should be used and, conversely, if there are not at least two sub-topics, then no subheads should be introduced. Styles named "Heading 1," "Heading 2," "Heading 3," and "Heading 4" are prescribed.

\subsection{Need to Optimize The Equipment in The Station to Reduce Unnecessary Ports}

The needle for intelligent substation in China, applied to the electrical equipment in most cases are imported from abroad, but these devices in terms of technology although has a certain degree of advanced, but when the production is based on the model of the power plant abroad to manufacture, so in our country in the power plant equipment procurement and analysis must be advanced and the structure of the equipment complexity are the key to quality assurance of equipment at the same time also need to be able to realize the intelligent substation equipment can realize the optimal allocation of effective equipment to reduce the complexity, but also can be some unnecessary window is reduced, to achieve better equipment operation, but also can meet the needs of energy saving and environmental protection. In addition through the understanding of the actual situation of China's Smart Substation after the initial stage, must be on the inside of the substation equipment can make a scientific and reasonable configuration, which can realize the resource can be effectively saved.

\subsection{Strengthening The Optimization of Safety}

For the smart substation, the relay protection device to a certain extent are based on IEC61850 standard system as the main basis, but especially in the implementation of unified release, can be completely transparent for the network environment, and then make the protection system in the actual operation, will not only face more attacks, but also a threat to information security, so should the system safety analysis well, IEC61850 standard system of safety effective regulation, so the need to constantly sum up the previous management experience, combined with the security aspects of developing effective strategies to optimize safety.

\subsection{Strengthening Reliability Optimization Analysis}

Intelligent substation relay protection has been implemented in full digital construction to relatively many power electronic devices exist to protect the structure in the process, this is not only for its substation operating stability was enhanced, while its security plays a role can not be ignored, 
to further meet the social life and production of power network operation process request. But the selection process of power electronic equipment, it should develop scientific and rational design in accordance with the actual situation, to strengthen the rationality of the design scheme, and promote its application effect, the purpose of doing so in order to reduce the impact of external factors on the existence of information, avoid the problem of synchronization in a certain extent, or electromagnetic capacitance etc. the problem. To protect the stability of the running process of the system are reduced, combined with the characteristics of protecting structure in the process of electronic equipment is easily affected, should develop effective strategies to enhance the reliability of the system operation process, for example: cable application is quite stable, through the realization of the system self redundancy technology, aiming at the unreasonable content can be the first time issued a warning, also can produce certain protective action.

\subsection{Optimization Analysis of Real Time}

An important feature of an electromechanical protection process in Smart Substation is real-time, in the process of protection structure design, often by the time delay combiner link propagation delay, switch in the exchange process and a series of restrictive factors, seriously affect the effect of power station number words interactive device in the transmission process, leading to transmission errors to a certain extent beyond the allowable range. Combined with the analysis of the operating conditions, the main factors that occur in the actual transmission of the digital transformer sampling value in the actual transmission are the combiner queuing and the switch forwarding. For combiners, there will be a queuing process when the data is transmitted by the collector. Usually, there will be an extra waiting time in the process of receiving the collector. At the same time, because the switch performance system installation is different, so in the process of operation will be delayed, if the information forwarded in the process should ensure all the data sent after the success in the implementation of the next forwarding, affect the real-time protection system, to develop effective strategies to optimize.

\subsection{Optimization Analysis of Strengthening Synchronism}

Intelligent substation, in the process of relay protection digital construction, in normal operation, usually there will be data synchronization problem. Is the output of the merging unit called the data sampling time information signal process, it can eliminate the error between the phase and the amplitude of the electrical quantity to a certain extent, so as to continuously optimize the mechanical and electrical protection equipment, ensure access to data and information has been set at the same time. If the synchronization signal is lost, the data collected at last must have error. So in the implementation of continuous optimization and design of its aspects, not only do the over-current protection, but also good overvoltage protection, the protection principle is relatively simple, and the protective action of the input signal amplitude is correct only proposed to go, but rarely require synchronous signal, so the protection action in the process if the synchronous signal loss, also do not have a huge impact on the protection action.

\subsection{Continuous Normalization of Device Interface Settings}

At the present stage, most of the electrical equipment purchased in the process of building smart substations originated from abroad, and basically belong to some well-known enterprises in some industries. Although there are advanced relatively high electrical equipment purchased from abroad, but these devices are in the design ideas, combining the actual situation of substation based on the framework, whether the interface position or shape, etc. are designed in accordance with the national machinery and equipment, and the actual situation of substation in China there are many different. Such objective conditions to a certain extent so that the relevant staff in the purchase of electrical equipment, full analysis and Research on the actual working condition and stability of substation equipment in operation, it will further as the main reference data to optimize the substation electrical equipment, reasonable to reduce number of electrical equipment, to ensure standardized management interface. The number of Smart Substation equipment is reduced, and the interface is also optimized. The practical operation steps of substation electrical equipment are reduced, and at the same time, the working efficiency of intelligent substation is enhanced, which fully ensures the intellectualization degree of intelligent white power station is strengthened. 


\section{Conclusions}

Through the above study results, in short, intelligent substation mainly as an important component of smart grid in China, in the construction, the core technology is for the relay protection technology, so in the core technology at the same time, it can promote the intelligent substation construction of our country to improve the effect. The safety of substations and can also be comprehensive, to promote the development of China's power grid toward intelligent direction constantly, promote the safe and effective operation of power grid in China, for society, for people to better service.

\section{References}

[1] Liu Haoyu, floating Ming, Dong Leichao. The research and application of automatic test system [J]. power system protection and control of intelligent substation relay protection device, 2015,43 (01): 40-44.

[2] Wang Tongwen, Xie min, Sun Yueqin, Shen Peng. Reliability analysis of relay protection system in Smart Substation [J]. power system protection and control, 2015,43 (06): 58-66I.S. Jacobs and C.P. Bean, "Fine particles, thin films and exchange anisotropy," in Magnetism, vol. III, G.T. Rado and H. Suhl, Eds. New York: Academic, 1963, pp. 271-350.

[3] Ni Yimin, Yang Yu, fan Chen, Guo Yanxia, Dou Renhui, Huang Fang. Two smart substation equipment integrated solutions [J]. automation of electric power systems, 2014,38 (03): 194-199.

[4] Cao Nan, Wang Zhiming, Li Gang, Li Bing, Wang Dongqing. Preliminary study on dynamic reconfiguration of the two system of Smart Substation [J]. automation of electric power systems, 2014,38 (05): 113-121.

[5] Ji Ling, Li Zhongming, Jiang Yanjun, Qiu Yutao. Smart Substation two system simulation test and integration test of new mode of exploration and research of [J]. power system protection and control, 2014,42 (22): 119-123. 